\title{
NUMERICAL SIMULATION OF FRICTION STIR WELDING OF ALUMINIUM PLATE
}

\author{
R. Jančo, P. Élesztos, L. Écsi, P. Šlesar*
}

\begin{abstract}
Friction Stir Welding (FSW) is one of the most effective solid state joining processes and has numerous potential applications in many industries. The aim of this paper is to describe the thermal-fluid and mechanical simulation of FSW using the finite element method in program SYSWELD. The simulation of FSW process requires the modelling of the complex interaction between thermal, metallurgical and mechanical phenomena. Thermal-mechanical results from the numerical simulation using SYSWELD are here presented for aluminium alloy.
\end{abstract}

Keywords: Friction Stir Welding (FSW), aluminium alloy, Finite element method, thermo-fluidmechanical model.

\section{Introduction}

Friction stir welding (FSW) is a relatively new joining technology which was developed and patented in 1991 by The Welding Institute (TWI), in the United Kingdom [Chen and Kovacevic (2003)]. A schematic principle of friction stir welding process is illustrated in Fig. 1 [Janco (Ecsi and Elesztos)].

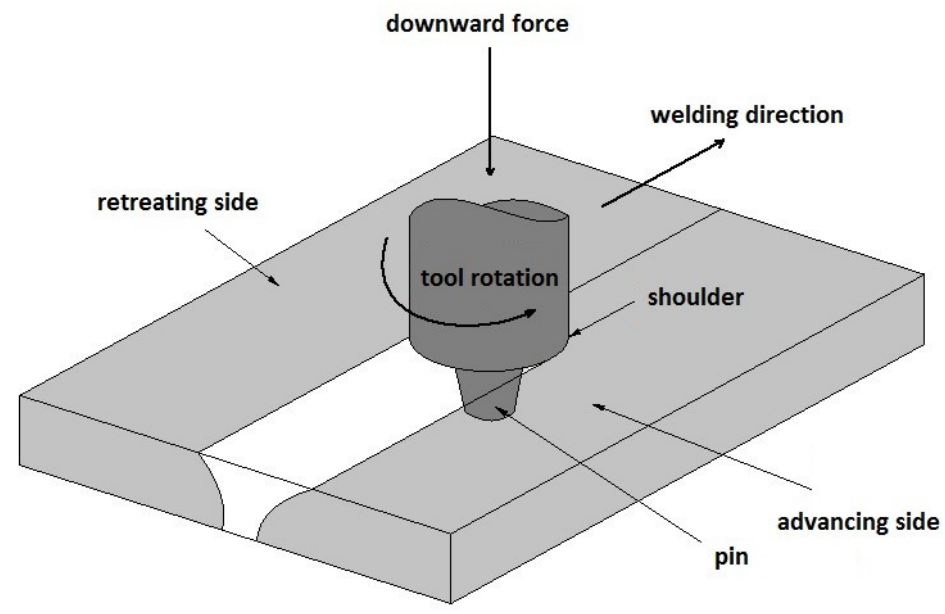

Fig. 1: Principle of FSW

This welding technique is extensively applied to the automobile, aerospace and shipbuilding industries [Frigaar Grong and Midling (2001), Feulvarch and Robin (2007), Janco (Ecsi and Elesztos), Janco (Ecsi and Elesztos)].

Prof. Ing. Roland Jančo, PhD., Prof. Ing. Pavel Élesztos, CSc., Assoc. Prof. Ing. Ladislav Écsi, PhD., Ing. Peter Šlesar: Institute of Applied Mechanics and Mechatronics, Slovak University of Technology in Bratislava, Faculty of Mechanical Engineering, Nám. slobody 17; 812 31, Bratislava; SK, roland.janco@ stuba.sk, pavel.elesztos@ @stuba.sk, ladislav.ecsi@stuba.sk, peter.slesar@stuba.sk 


\section{Solution of Friction Stir Welding in SYSWeld}

For the numerical solution we used the program SYSWeld with the FSW (Friction Stir Welding) module. The FSW module solves the weld joint in the three steps. This step is described in Janco (Ecsi and Elesztos). For numerical simulation was used aluminium alloy $\mathrm{AlMg} 4.5 \mathrm{Mn} 0.7$ with material properties presented in Janco (Ecsi and Elesztos), which is function of temperature. Blacking plate was made by steel again material properties is in Janco (Ecsi and Elesztos). For the welding process we used following properties: the friction coefficient is 0.238 , linear welding velocity is $1.67 \mathrm{~mm} / \mathrm{s}$, tool rotation velocity $41.89 \mathrm{rad} . \mathrm{s}^{-1}$, room temperature $15^{\circ} \mathrm{C}$ and heat exchange coefficient for convection $19 \mathrm{~W} /\left(\mathrm{m}^{2} . \mathrm{K}\right)$. Theoretical background and equations of FSW module is described in Janco (Ecsi and Elesztos).

\subsection{Thermo-fluid model}

The thermo-fluid flow in FSW for the stationary step in SYSWELD®. The all numerical results were compared with experimental measurement by thermo-camera and thermocouples. In the Fig. 2 is the mesh

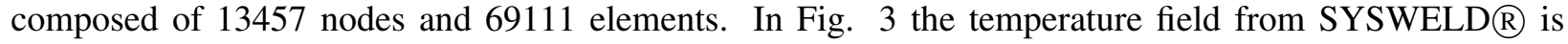
presented.

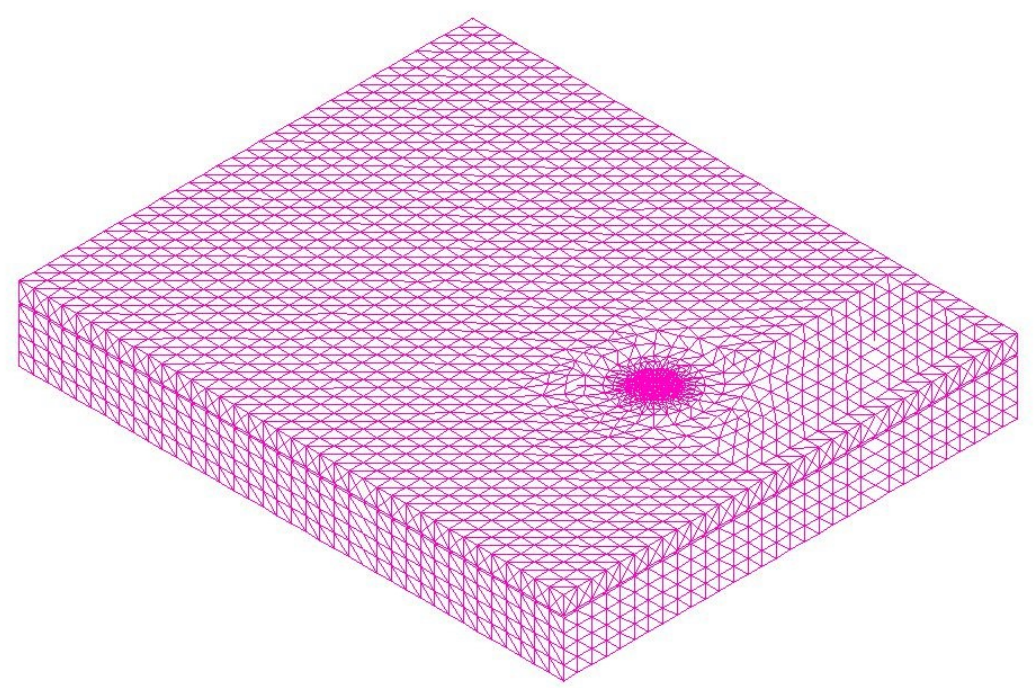

Fig. 2: FEM model of sheet and backing plate

\subsection{Thermo-mechanical model}

The boundary conditions for the mechanical analysis are shown in Fig. 4 and the thermal field from thermofluid analysis was used. The finite element model is shown in Fig. 5, which consists of 63261 elements and 70340 nodes. Results from thermo-mechanical analysis are presented from the Fig. 6.

\section{Conclusions}

The paper present the possibility of numerical solution of friction stir welding. In section 2.1 the numerical solution of the thermal field is presented with the thermo-fluid analysis using the SYSWeld software and the FSW module. The temperature field from numerical solution is presented in Fig. 3. The result of the numerical solution of the thermal field calculated with SYSWeld and measured with the camera are in a good agreement. Maximum temperature is $511,911{ }^{\circ} \mathrm{C}$ at time $225 \mathrm{~s}$ in Fig. 3. Results from the thermomechanical analysis is presented in Fig. 6 for time $225 \mathrm{~s}$. The maximum value of stress is $145.5 \mathrm{MPa}$. Modeling and measurement of the temperature and stress evolution in the FSW of AlMg4.5Mn0.7 Al alloy is conducted, and the experimental values validate the efficiency of the proposed model. 


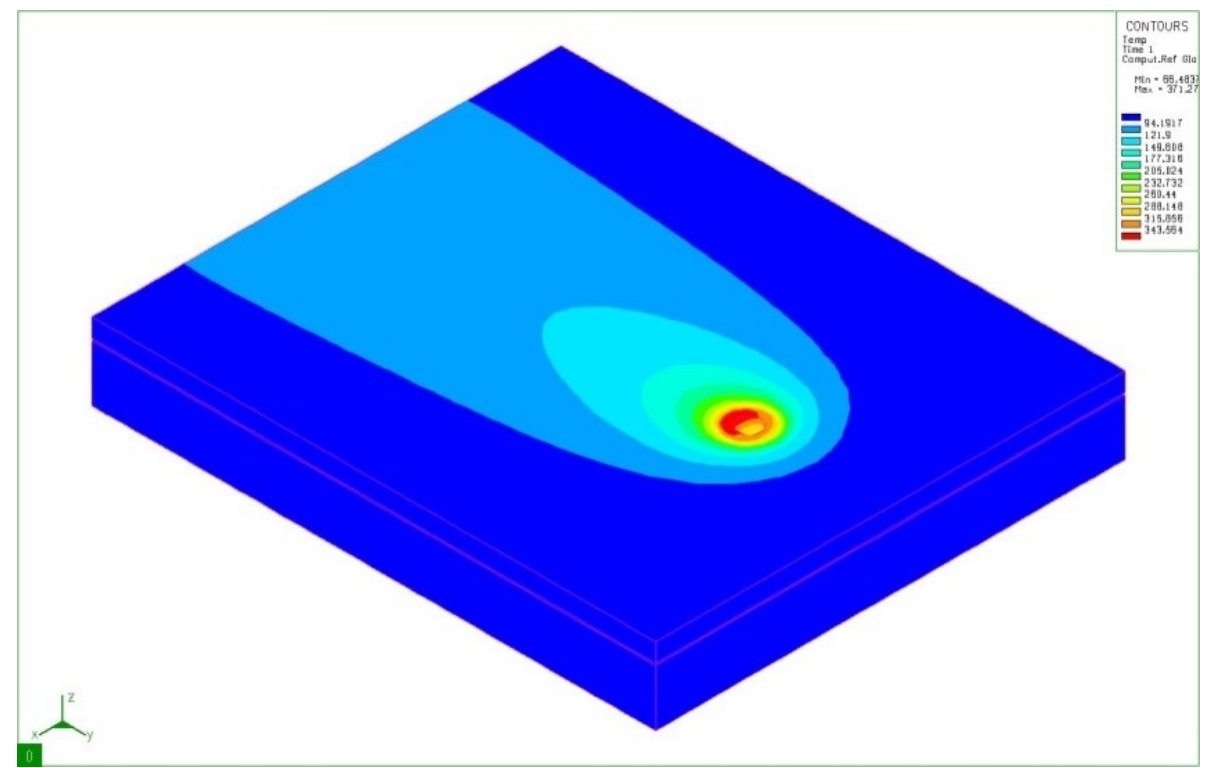

Fig. 3: Temperature field at time $225 \mathrm{~s}$

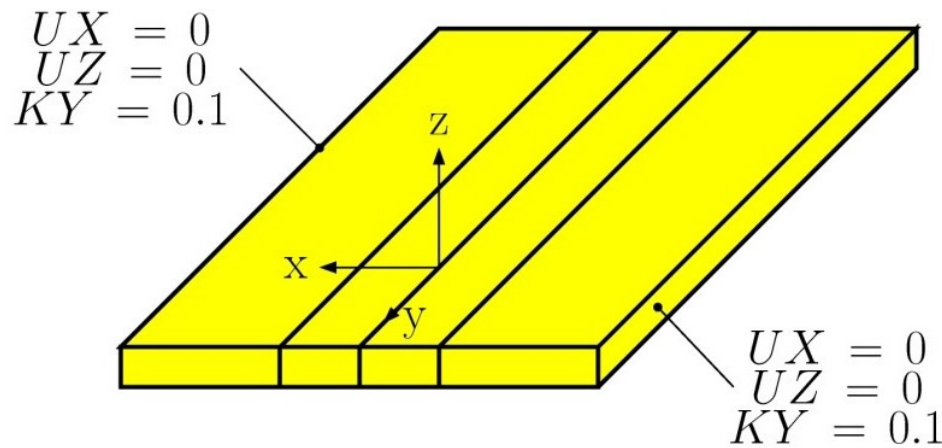

Fig. 4: Boundary condition for mechanical solution

\section{Acknowledgments}

This publication is the result of the project implementation: Research of friction stir welding (FSW) application as an alternative to melting welding methods no. 26240220031 supported by the Research \& Development Operational Programme funded by the ERDF and funding from the KEGA 017STU-4/2018 grant resources are greatly appreciated.

\section{References}

Chen, C.M., Kovacevic, R. (2003) Finite element modeling of friction stir welding - thermal and thermomechanical analysis. International Journal of Machine Tools \& Manufacture, 43, pp 1319-1326.

Frigaard, Ø., Grong, Ø., Midling, O.T. (2001) A Process Model for Friction Stir Welding of Age Hardening Aluminium Alloys. Metallurgical and Materials Transactions A, 32A, pp 1189-1200.

Feulvarch, E., Robin, V., Boitout, F., Bergheau, J.M. (2007) 3D Modelling of Thermo fluid Flow in Friction Stir Welding Including Metallurgical and Mechanical Consequences. Mathematical modelling of weld phenomena, 8, pp 1-24.

Jančo, R., Écsi, L. and Pavel Élesztós, P. (2016) FSW Numerical Simulation of Aluminium Plates by Sysweld - Part I. Strojnícky casopis - Journal of Mechanical Engineering, 66, 1, pp 47-52.

Jančo, R., Écsi, L. and Pavel Élesztős, P. (2016) FSW Numerical Simulation of Aluminium Plates by Sysweld - Part II. Strojnicky casopis - Journal of Mechanical Engineering, 66, 2, pp 29-36. 


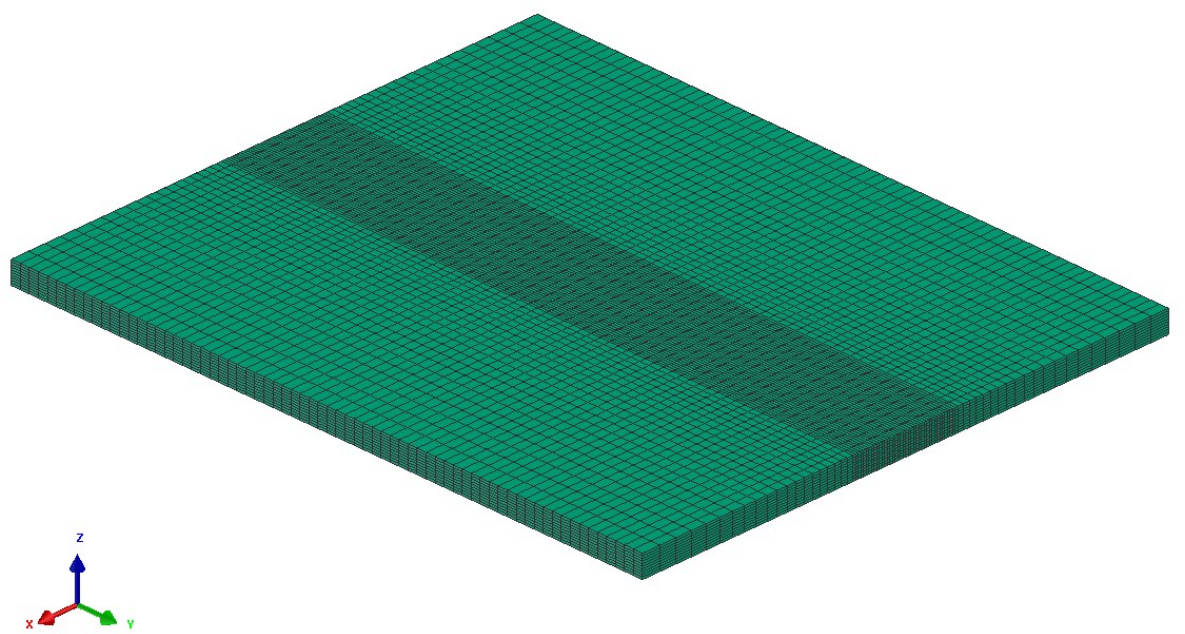

Fig. 5: FEM for the thermo-mechanical analysis

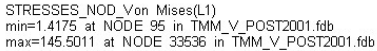

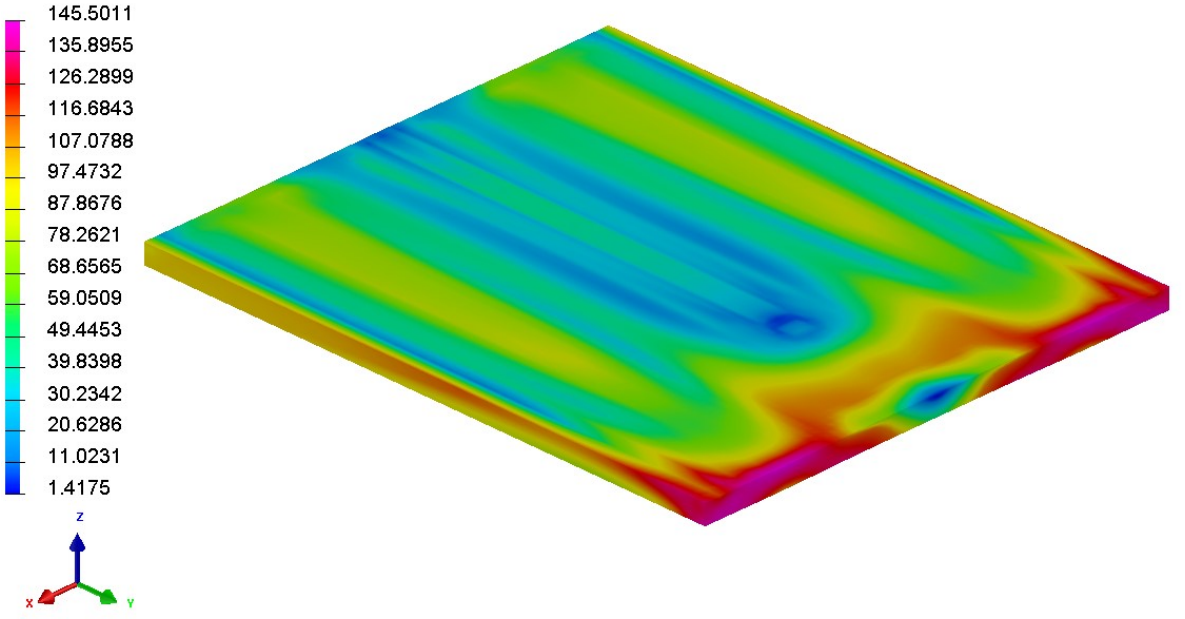

Fig. 6: Von Mises stress field (MPa) 